https://helda.helsinki.fi

\title{
Crafticulation as a method of knowledge creation
}

\section{Lahti, Henna}

2021-09-01

Lahti , H \& Fernström , P 2021 , ' Crafticulation as a method of knowledge creation ' , Craft Research , vol. 12 , no. 2 , pp. 183-204 . https://doi.org/10.1386/crre_00049_1

http://hdl.handle.net/10138/335873

https://doi.org/10.1386/crre_00049_1

Downloaded from Helda, University of Helsinki institutional repository.

This is an electronic reprint of the original article.

This reprint may differ from the original in pagination and typographic detail.

Please cite the original version. 


\title{
Crafticulation as a method of knowledge creation
}

\author{
Abstract \\ Our aim in this article is to introduce the idea of 'crafticulation' as a part of scientific method \\ and to present a case study related to it. A novel course, Materializing in Craft Science, (5 \\ ECTS), was offered in the first year of the craft teacher master's degree at the University of \\ Helsinki. The aim of the course was to pilot a method of crafticulation by materializing \\ theoretical mind maps. Crafticulation consists of the words, 'craft' and 'articulation' and \\ further, crafticulation is seen as a part of practice-led research in which craft plays a key role \\ in eliciting a wide spectrum of knowledge. Our research question is how crafticulation \\ emerged in students' inquiry processes. The research data included 20 individual mind maps, \\ materializations, and reflections of the course. Based on theory-driven data analysis, the \\ results indicated that many students used crafticulation for demonstration purposes. For \\ example, they tested the connection between their craft-making process and well-being. \\ Another approach was to convey a certain experience by way of crafticulation. In some cases, \\ crafticulation was linked to analogies and metaphors in learning theoretical concepts. \\ Furthermore, the students found new avenues in which to reflect research topics and to \\ deepen their inquiry processes.
}

Keywords: crafticulation, craft education, craft science, creative process, inquiry process, knowledge creation, research method

\section{Introduction}

'Crafticulation' is not a new concept; it was introduced over ten years ago at the NordFo Conference related to Crafticulation \& Education. It was defined on the conference web site as '(Craft + articulation); - how the culture of craft is constantly made, unmade, and remade' (Gulliksen 2009: 199). At the conference, crafticulation was connected to the practice-led research methodology and explorations of ways of knowing through craft works and reflections (e.g., Anttila 2009; Gray and Burnett 2009). In this paper, we have continued discussion of crafticulation as a method used in knowledge creation. In pedagogical settings, knowledge creation is not just a personal experience but also a collaborative sense-making process. Nonaka and Takeuchi (1995) refer to 'knowledge redundancy', that is, some overlapping information shared by participants. This facilitates knowledge transmission as it encourages communication and enables individuals to sense what other people are trying to articulate. The role of the researcher as apprentice has been important in anthropological practice (e.g., Ingold 2013; Marchand 2010). In such research, it becomes clear that there are certain forms of knowledge that cannot be understood simply through observation but require being with and doing things with practitioners.

If we think of crafticulation as part of a research method, many similarities to practice-led research and research-led practice in the creative disciplines can be found (cf. Smith and Dean 2009). Questions, theories, data and methods are central elements in all research settings and also in crafticulation made by a maker-researcher or researcher-maker. Thus, materializing is a tool for handling information and understanding. According to Mäkelä (2007), the crucial task for each practice-led research project is to give a voice to the artefact. This requires interpretation of an artefact in a certain context so that the artefact can tell its 
story. Her study shows the ways in which a creative process can be understood as a process of inquiry (e.g., female figures transformed onto ceramic slates, see Mäkelä 2007: 162).

Thus, it is not as essential to reflect on whether knowledge precedes the exercise of craft, or whether the experience of practice produces knowledge in the first place. Crafticulation can be based on either research-led craft or craft-led research. As a matter of fact, knowledge creation underlines the importance of the two-fold process of making and reflecting, and the potential of this process to reveal the maker's insights, knowledge, or understanding (Farber and Mäkelä 2010).

According to Ingold (2009) crafting corresponds to weaving materials that bring out the itinerant, improvisatory and rhythmic qualities of making. Sennett (2008) has stated that the craftsman develops the skill of anticipation - the ability to anticipate what the material should become in its next stage. In this evolution, the maker's tacit knowledge serves as an anchor, whereas their explicit awareness serves as critique and corrective (Ibid: 50). Zmyślony (2010) has summarised the Polanyian idea of tacit knowledge according to its two basic concepts. The first refers to the inexpressible particulars indwelled in the knower's body and experience, while the second refers to the skill of integrating these particulars into a meaningful whole. However, Ingold (2013: 109) points out that expressions of tacit knowledge are multifaceted, and 'we can tell of what we know through practice and experience, precisely because telling is itself a modality of performance that abhors articulation and specification'. Likewise, Nasseri and Wilson (2017) stated that craft dialogue differs from verbal dialogue, that is, craft dialogue embodies both consciously and unconsciously obtained knowledge, as opposed to verbal dialogue which only conveys conscious information. Crafticulation is both an internal and an external dialogue involving senses, thoughts, feelings and intuition, and further materials of the craftsman and crafts.

\section{Crafticulation as a part of practice-led research}

In this article, we have relied on Nordic craft research that challenges traditional academic research and provides an authorised domain for craftspeople within academia (Anttila 2009; Kokko, Almevik, Høgseth and Seitamaa-Hakkarainen 2020). We focus on the prospects of craft in the practice-led research methodology. In our thinking, crafticulation is an umbrella concept which allows craft to arise as a result of a study, rather than as an object of study. Materialization, which appears later in the case study, is an educational tool within crafticulation which provides a new strategy for undertaking craft studies, a way of making visible the object of one's theoretical thinking.

Traditional craft teacher education divides theoretical studies and craft making rather than integrating them. We suggest that crafticulation could represent an integrative activity that would combine theoretical insights with the craft making process in a reciprocal way, not a contrasting way. For example, Barrett (2007) has argued that artistic research related to lived experience and direct engagement with materials and objects provides a crucial alternative mode of knowledge production compared with the scientific method described by Latour. However, craft is primarily perceived and understood as skilful making rather than an intellectual activity. Besides, material and technical mastery are important components in craft education; there are novel studies in various educational stages (e.g., Räisänen 2014; Groth and Mäkelä 2016) in which the driver of craft is vision and concept.

In the field of visual art practice, Throp (2016) highlights the need for a pedagogical strategy for theorizing out of practice that is based on knowing the world theoretically after 
understanding it through action and reflection. Reflection may be a personal process that usually results in some change for the individual in their perspective of a situation or creates new learning for the individual. However, it can also be an interpersonal process. According to Anttila (2009), there are three forms of reflection in the phenomenon of expanded knowledge, or in crafticulation: self-reflection, co-reflection and object-oriented reflection. Reflection, dependent as it is on memory, (and conducted after the creative act or as close to it as possible), can unfortunately be a fallible method. It often fails to offer insights into the cognitive processes of creation that are frequently the focus of practice-based research (Skains 2018). For this reason, reflective practice could be understood as being more like an intuitive model labelled tacit knowing, an experiential-intuitive model, than a Schönian type of stop and think (see Hébert 2015). According to Anttila (2009), knowledge resulting from creative thinking and intuition is derived from a person's internal perceptions, experiences and insights, and further, this kind of reflection is qualitatively different from the critical reflection of perceptible entities. Respectively, educators in the field of craft and design must rule in all forms of reflection during students' inquiry processes.

Explicit reflection on process provides a rationale for the integration of theory and practice, whereas 'material evidence' - theoretical conceptualization of foundational knowledge in art research, is based on a form of ostensive definition without significant use of text for theoretical reasons (Thornquist 2015; Throp 2016; see also Anttila 2009). Research findings concerning craft reflections show that we are dealing with the expanded concept of knowledge involving all the knowledge elements previously mentioned (cf. Anttila 2009). These include not only verbal, propositional knowledge, but also tacit, procedural, and experiential knowledge, intuition, and emotional knowledge. Crafticulation is the result of a mode of knowing and relating to one's own self and to the environment. This knowledge is responsive to uncertain situations. As stated by Adamson (2007: 169) 'Thinking through craft is a useful exercise, and never more so than when it creates uncertainty'.

Craft knowledge is based on dialogue between experiential and propositional knowledge (Niedderer and Townsend 2014). Experiential knowledge and embodied experiences with the environment can be articulated through practice-led research (e.g., Groth, Mäkelä and Seitamaa-Hakkarainen 2015). In Marchand's (2010: S18) words, 'embodied knowledge is more than merely skilled practice and performance, and that the body plays a key role in the making and recall of a wide spectrum of knowledge, including the conceptual kind'. When learning through experience, exploration is a singular event. As a result of Groth and Mäkelä's (2016) case study, they considered material exploration to be an important part of a student's development into a skill-full designer. They highlighted both physical material exploration and imaginary material exploration. The latter form of exploration is based on previous bodily experience with the imagined materials. They wrote that "when imagination reaches its limits, the physical material exploration and the resulting prototype takes the concept to the next level, that is the experiential level, where the design may be experienced bodily' (Groth and Mäkelä 2016:18).

There is a need for pedagogical interventions that aim to promote the development of deep conceptual understanding of challenging concepts. The dialogue between experiential and propositional knowledge provides opportunities for testing propositional knowledge in the field of craft and design. As Niedderer and Townsend (2014) have pointed out, experiential knowledge can generate data and validate hypothetical implications. And further, analysing experiential data in connection with the relevant literature can generate an understanding of the subject studied (Mäkelä and Nimkulrat 2018). For example, Nimkulrat's $(2010 ; 2012)$ 
craft productions were built around a research problem the aim of which was to derive experiential knowledge that would deliver data and prove some hypothetical implications related to the role of craft in a practice-led research process. In another example, Lehmann (2012) focused on making as knowing and gave an example of the reasoning (apprehending scientific knowledge, to some extent) in using techniques that led to conceptual change in the condition of making, exemplified by Issey Miyake's 'Pleats Please'.

In her dissertation, Aakko (2016) brought out the concept of skilful materiality, which relates to the artisanal elements of the design and making processes. This highlights the significance of the making process itself, drawing attention to skill, craft and materiality as the foundations of artisanal design and production. The concept of skilful materiality symbolizes not only material quality, but also aesthetic choices. Skilful materiality also provides potential for materializing values. It is possible for the designer to articulate personal insight through visual and technical design elements and contribute to aspects of culture or society at large. Respectively, Niedderer and Townsend (2014) recognized experiential and emotional knowledge as agents of intrinsic understanding, interpretation and judgement of craft's affinity with human values. Similarly, crafticulation may offer a vision for the development of both personal and sociocultural issues.

\section{Research context}

The main objective of our research project was to develop a new way to combine theoretical and material thinking in the context of craft science. In the Nordic languages, the concept 'science' also covers the humanities and social sciences not just the natural sciences (see Kokko et al. 2020). In Finnish universities, craft science belongs to the faculty or department of educational sciences since the discipline is based in craft teaching education programmes. During the past few decades, craft teachers have specialized either in textile work or in technical work as subject teachers in the school system, as well as craft and design experts. Recently, craft teaching education has faced new challenges related to multi-material competence, comprise a variety of techniques and materials, such as textile, wood, metal, electricity, programming etc. The approaches cover both traditional and contemporary aspects. The students get a broad master's-level education in craft studies and pedagogy including teaching practice. As part of their study, the students learn various research methods. In this article, we have focused on methods and ended up using a compound word 'crafticulation' because it represents making and dialogical in a unified manner. Our research question is as follows:

How has crafticulation emerged in students' inquiry processes?

To test and develop the idea of crafticulation we offered the course Materializing in Craft Science, (5 ECTS) in the first year of the craft teacher master's degree at the University of Helsinki, in Finland. Twenty students participated in the course during its first implementation. The course covered the whole autumn term in 2018 and consisted of 26 lessons divided into seven separate sessions. At the beginning of the course, three publications (Adamsom 2007; Kouhia 2015; Nimkulrat 2012) were introduced to the students. As co-teachers in the course, we asked each student to frame a research question as a premise for the theoretical mind map and materializing, and hence the inquiry processes began by identifying questions that were stimulating and motivating to the students. 
Instructions for the assignment were purposely not too detailed but were formulated sufficiently openly to allow students to use their own imagination to address the work. In preparation for the mind maps, the students conducted literature and article searches to choose the relevant research inputs for their work. For their mind maps, they used tools such as Prezi, Instagram, Coggle, Flinga and MindMup. The students implemented a variety of craft techniques like sewing, embroidery, crochet, macramé, weaving, handmade paper, wire work, cloth painting and engraving. At the end of the course, each student also wrote a short reflection. Consequently, our research data consisted of 20 individual reports (theoretical mind maps and reflections) and materializations (19 crafts and a video).

\section{Theory-driven data analysis}

In this research, we adapted theory-driven data analysis in order to find out how crafticulation emerged in students' inquiry processes. We analysed the process and students' own research questions helped us in the classification. In previous research, Niedderer (2009: 66) stated that artefacts in the process of knowledge communication may be used:

- for demonstration purposes,

- to illustrate a problem,

- to convey a certain experience,

- to indicate process knowledge,

- to present the evidence of a creative exploration to find new avenues.

Based on the viewpoints presented in Niedderer's (2009) study, we found similar strategies from the students' inquiry processes. The five categories were: (1) testing theory/claims (2) explaining problems (3) conveying experiences (4) capturing knowledge, and (5) presenting new avenues. We found that creative exploration encompasses all five categories, not just the last one. In addition, the fourth category is also a matter of capturing either experiential or propositional knowledge related to the student's own research question not just indicating process knowledge.

The most common category was testing theory or claims (see Table 1). It turned up in eight cases of crafticulation. Some outputs were classified into two categories because it was impossible to select just one category in these cases. In this article, we have presented an example of each category. The cases selected are marked in Table 1.

Insert Table 1 about here

\section{Five cases of crafticulation}

\section{Case 1: Testing theory/claims}

Most of the students attending the Materializing in Craft Science course addressed a claim or theory in their materialization assignment. One of the students studied the impact of a flow state. She had learned that in such a state, a person forgets everything else, such as time and place. She was suffering from chronic pain. She combined the state of flow and her painful 
condition and tested whether she could reach such a state of flow that would enable her to forget her own pain, with the help of her craft skills and enthusiasm. Her question was: 'Can I free myself from the sentiments of pain that control me through the creative process? Has the concept of flow something to do with this?'

She sought relevant literature that would lead her to solve this problem in the best way possible. The identified literature she dealt with the subject of art therapy for adults with chronic pain and craft makers' descriptions of their stress-reduction. Her outcome was an embroidered textile collage which she called an Emancipation from Pain (Figure 1). She wanted to manifest the pain with their work. By doing this the student focused on emotional experiences (cf. Ojala et al. 2018) that cover both somatic experiences and flow experiences. One of the main results of the study was that emotional experiences seem to have a certain 'energy' and 'dynamic' in the craft process, which either advance or obstruct the process and encourage or discourage the craft maker (Ibid: 219).

Figure 1: Student materialization, impact of a state of flow on chronic pain. Photos: H. Lahti, 13 February 2019.

The student found the course 'interesting, opening new horizons on materialization'. She valued the shared experience with the other students, learning them and she confirming having experienced moments of 'flow' during the embroidery work. At the beginning of the course, she felt slightly uncertain due to the open formulation of the assignment and unfamiliarity of this novel method. As a result, her inquiry processes were both classified within the first category (i.e., testing theory/claims) and into the third category (i.e. conveying experiences), because she also conveyed an experience of her chronic pain by way of crafticulation.

\section{Case 2: Explaining problems}

Two students out of 20 used their materializations to illustrate a problem related to craft making (i.e., unfinished crafts and the pressure of self-made gifts). In the selected case, the student wondered why so many of her handicraft works were never finished. Therefore, the student's question was: 'Why do my works of handicraft remain unfinished and how does it feel?' The student collected all her unfinished items of handicraft, took photographs of them and wrote reflections on each item. She also looked more closely into the literature about the meanings of textile hobby crafts and one main reference in this process was Anna Kouhia's (2016) doctoral thesis. The student was also interested in artists diaries, and she decided to articulate this by way of a craft diary. In her reflection, she explained that:

... In my own project, I wanted to understand myself and my craft making. I wanted to bring a conclusion to something that has been un-completed. The working had a therapeutic effect. I was able to think not everything has always to be completed. I also got rid of a mental compulsion to bring the unfinished projects ready even through destroying the product.

The student had a strong vision to record an artists' diary as an inquiry process. Figure 2 presents some fragments of her craft diary. On the front cover, an unfinished frame weaving 
craft item leads to the pages of an old calendar with authentic marks. This calendar was used in 2018 and the student enclosed her crafticulations in the hectic schedule. In the next few pages of the diary, there are references to an unfinished woolly hat, rapid materializations inspired by pirates (i.e., reflection on unfinished crocheted pirate slippers), the best parts of children's knitted cardigans, and a finished sock. Besides explaining the problem in question, her multifaceted reflection and her diary represents a creative exploration to find new avenues between art and craft (cf. Niedderer, 2009). The student's thinking and working process can be seen as a 'manifestation' against or at odds with skilful materiality, at least in the traditional craft education context.

Figure 2: The fragments of the student's craft diary. Photos: H. Lahti, 12 February 2019.

\section{Case 3: Conveying experiences}

The students often tried to transfer certain experiences, such as of Finnish nature, rootlessness, traditional vs. modern symbolism, or chronic pain as in Case 1. In that case, the student experienced emancipation from pain by making embroidered metaphors. For example, she embroidered pulmonary alveoli using pearls (see Figure 1) and this kind of decoration represented making her life more bearable. Basically, it is necessary to consider one's own experience as a growth process, in which the student is within a world of active materials (cf. Ingold 2013). Respectively, the aim of crafticulation is not to carry out a preconceived idea but to join with and follow the forces and flows of material, in anticipation of what might emerge.

The selected materials in the cases corresponded to the experience to be articulated, such as transparent materials corresponding to the theme of rootless and plastic materials to the feeling of modernity. The student in Case 3 focused on the use of contrast (e.g., feminine masculine; knit-like - steel-like; light - heavy; matt - gloss). The student was skilful, particularly in macramé techniques and considered macramé to be soft and feminine in nature. She wanted to question her own experience, and at the same time, transform the feminine characteristics of macramé into something hard and masculine (see her moodboard in Figure 3). She decided to make armour using the technique, and ended up asking the question: 'What associations are generated by macramé armour?'

Figure 3: Armour made by the student; cotton yarn using the macramé technique. Photos by the student.

As her references she chose Nithikul Nimkulrat's articles $(2010 ; 2012)$ about material inspiration, and an article about armour, how it was high-tech in its time. It would seem that the student's and Nimkulrat's processes resemble each others closely if you compare Figure 3 to the examples in Nimkulrat $(2010 ; 2012)$. They both explored the relationship of materiality and expressivity with various knotting techniques. As an expert craft maker, the student experienced the material as an active element in the craft process, thus limiting or inspiring new ideas: 
During my macramé work I ponder on visual, functional and structural alternatives. By using my crafting skills, I finally decided on solutions that at that moment seemed appropriate for the work and as functional as possible. I did not prepare an actual sketch of the armour nor a clear plan; I wanted the macramé technique to lead me to the right solution.

As pointed out in the reflection, materiality is an indistinguishable part of the maker and the maker part of the material. All this is in turn part of a larger whole, such as cultural background, in this case degrees and extremes of femininity or masculinity?

\section{Case 4: Capturing knowledge}

Unlike the other categories, the category of capturing knowledge was data driven. Common to all three cases in this category was capturing knowledge during inquiry processes. These materializations were a novel piece of textile work, a traditional rag doll and a video film. Above all, this video maker focused on capturing experiential knowledge related to her inquiry process.

In our case example, the student wanted to learn more about the Northern Lights and know 'What makes the Northern Lights happen and why?' She found out that the Northern Lights are caused by the charged particles (protons and electrons mostly) of the solar wind, and further, noted that the details of the phenomenon are quite complicated. The student's first aim was to materialize the Northern Lights analogically, but she realized that it was impossible. She was inspired by some articles related to the role of analogies and metaphors in learning science and decided to materialize the Northern Lights by using metaphors.

In her reflection, she wrote that Jakobson and Wickman (2008) concluded that artistic methods can complement scientific education and vice versa.

Similarly, I was able to observe how acquiring scientific knowledge and in particular focusing on the essentials could be enhanced by material expression. If I had studied the topic for the exam in traditional ways, I would have tried to absorb too much dispersed information too quickly from all the data available to me. The assignment helped me to concentrate on the information that was possible for me at my level, by means of materialization.

She managed to create a 'material mind' alongside theoretical mind mapping (Figure 4). The final textile work is like a material mind map because it comprises all the essential information the student found during her inquiry process concerning an understanding of the Northern Lights.

Figure 4: The theoretical mind map with the references and the final textile work. Photo: H. Lahti, 11 December 2018.

\section{Case 5: Presenting new avenues}

In our study, four cases were classified in the category of presenting new avenues. This means that these four students achieved something new at the level of craft science as well as at individual level. Common to the cases was that these four students considered the 
phenomenon of expanded knowledge and the nature of being (i.e., philosophy of science) more clearly than the other students. For example, two students were inspired by autoethnographic cinema (Kouhia 2015) and explored this new form of research through their inquiry processes. Another student studied the relationship between craft and something quite abstract and virtual (Figure 5).

Figure 5: The multi-element craft in the exhibition. Photos: H. Lahti, 11 December 2018.

The student had several preliminary research problems: 'How to materialize the virtual? Codes materialized? Digital and pixels, what are they in material form? Is it ever useful to materialize the digital and virtual? How to materialize something in a momentary, disintegrative, fashion?' She read a lot on hi-tech, electronic textiles, and about post-digital time, but also about the tradition of self-making. Following a process with many stages, the outcome was the collection of handmade paper and glass works, as shown in Figure 5. In addition, the student made and published videos, such as 'Missing bit' and called her project 'Coded messages in a bottle and flying carpets - studies of momentary materialization of digital and virtual'.

In this case, the theoretical mind map and craft practice developed in a mutually reinforcing cycle. The student wrote in her reflection:

During the course, I learned a lot about the virtual world and its functioning. I took the challenge to step into a realm which is slightly odd and unfamiliar to me. I am not an IT or electronics enthusiast but since this process, I have become more open to this world and especially to the opportunities to create added value by interacting with craft. The project encouraged me to investigate the interplay of craft with IT and electronics further. In this process my observations remained superficial, incubating ideas of sorts, which I could develop much further.

\section{Discussion}

Traditionally, academic research courses and craft courses have been separate at the University of Helsinki. In our project, we were trying to combine students' inquiry processes with their creative practices. Our course, Materializing in Craft Science, succeeded in facilitating knowledge creation as a continuous dialogue between propositional and tacit knowledge, at least in most of the cases. Points of resemblance to Nonaka and Takeuchi's (1995) theory of knowledge creation can be found with the exception of the context 'university vs. business'. Based on the similarities of the iterative transitions between propositional and tacit knowledge, we defined crafticulation as a method of knowledge creation. As such, it could serve the academic research process in a variety of contexts.

An extraordinary open assignment, at least in craft education, enabled varied inquiry methods, processes and outcomes. The course outcomes are not actual academic research works but they could be developed in that direction. Working with theoretical mind maps and crafts connected propositional knowledge to experiential knowledge and generated new insights into the role of craft in the academic field. According to Niedderer and Townsend 
(2014), experiential knowledge and organized inquiry offers opportunities to validate hypothetical implications. This approach to testing of propositional knowledge by way of creative exploration was found to be the most common type of crafticulation among our cases.

Reflection was considered as an experiential-intuitive way in which material evidence and conceptualization, without significant use of text, become more obvious. We believe that it was easier for craft students to think and work creatively when the emphasis of craft science studies was on materials and making not on writing a scholarly text or essays (cf. Collanus and Heinonen 2012). Because tacit knowledge by its nature evades verbalization and therefore evades communication, dissemination and knowledge sharing, there may be problems concerning the communication of the outcomes of research (Niedderer 2007). For this reason, 'externalization' by articulating knowledge variously is a key element of knowledge creation (Nonaka and Takeuchi 1995). When tacit knowledge is explained through practice and experience, it becomes the basis of new knowledge and the iterative nature of knowledge creation. However, it is a great challenge for students to the search for a perceptive sensibility and an epistemological proposal at the same time.

\section{Conclusions}

Crafticulation is like a miniature version of Mindful Inquiry (Valentine 2011). Our course Materializing in Craft Science took only a couple of months, whereas the Mindful Inquiry model requires a ten-year snapshot of craft practice. However, in both cases, craft makers developed their knowledge of materials and techniques, people and culture in parallel with their craft practice. This activity might also lead to innovations within their practice. We can agree with Gulliksen (2009) that crafticulation may be both a means and an end.

Crafticulating (i.e., theoretical mind mapping and materializing) includes both the process and the outcomes of the process. In this process of progressive inquiry, students search for and are working with new information that allows reasoning and problem solving to proceed. Each note on a mind map or action with material feeds back information allowing students to see, often by accident, new directions for their original thoughts.

The materialization process seems to be an appropriate tool to provide the results we have attributed to the crafticulation method for knowledge creation discussed in this article. In reference to the theoretical background and the findings of the study, we can conclude that crafticulation could serve as a method to

- explain inquiry problems and contexts,

- analyse and understand complex concepts,

- validate hypothetical implications,

- practice skilful materiality,

- provide material (and virtual) evidence.

In the future, other disciplines (along with craft science), could also use crafticulation as a method for knowledge creation. For example, material mind maps could be used to learn scientific concepts in science education. Craft science could also draw on other disciplines' research paths. For example, Pentassuglia (2017) has presented three main uses of dance in the academic field. These three perspectives represent the three 'souls' that art could have: (1) a lens and habitus to observe reality (2) a research method and instrument for data 
collection and (3) an alternative form of data representation. These perspectives are complementary to our research findings and conclusions.

There are a few ideas for the development of this course that we have identified as part of this research project. At the beginning of the course, it is important to illustrate the phases and the role of materialization and the inquiry process to the students (e.g., figure in Niedderer 2013: 11). Stating the definition of the research question to be studied becomes especially important before the actual creative exploration and artefacts in research. However, the question can be refined during the inquiry process. Also, it is important to emphasize that students read thought-provoking studies with making not just beforehand or afterwards. In the future, we would like to develop the process of co-reflection during the peer reviewing session. This would mean a shift from a dialogical approach to a trialogical approach.

\section{References}

Aakko, M. (2016), Fashion in-between: Artisanal Design and Production of Fashion, Aalto University publication series, Doctoral dissertations 88/2016, Helsinki: Aalto University.

Adamson, G. (2007), Thinking through Craft, Oxford: Berg.

Anttila, P. (2009), 'Expanded concept of knowledge in research of art and craft works', in L. K. Kaukinen (ed.), Proceedings of the Crafticulation and Education Conference, Helsinki: NordFo, pp. 14-21.

Barrett, E. (2007), 'Experiential learning in practice as research: Context, method, knowledge', Journal of Visual Art Practice, 6: 2, pp. 115-124.

Collanus, M. and Heinonen, T. (2012), 'Arts making as an act of theory', in T. M. Quinn, J. Ploof and L. J. Hochtritt (eds), Art and Social Justice Education: Culture as Commons, New York: Routledge, pp. 83-88.

Farber, L. and Mäkelä, M. (2010), 'Exploring through practice: Connecting global practiceled research approaches with South African production', in L. Farber (ed.), On making:

Integrated approaches to practice-led research in art and design, University of Johannesburg, South Africa, pp. 7-27.

Gray C. and Burnett G. (2009), 'Making sense: an exploration of ways of knowing generated through practice and reflection in craft', in L. K. Kaukinen (ed.), Proceedings of the Crafticulation and Education Conference, Helsinki: NordFo, pp. 44-51.

Groth, C. and Mäkelä, M. (2016), 'The knowing body in material exploration', Studies in Material Thinking, 14, article 02.

Groth, C., Mäkelä, M. and Seitamaa-Hakkarainen, P. (2015), 'Tactile augmentation: A multimethod for capturing experiential knowledge', Craft Research 6: 1, pp. 57-81.

Gulliksen, M. S. (2009), 'Teaching form quality in craft', in L. K. Kaukinen (ed.), Proceedings of the Crafticulation and Education Conference, Helsinki: NordFo, pp. 199205. 
Lahti, Henna and Fernström, Päivi (2021), 'Crafticulation as a method of knowledge creation',

Craft Research, 12:2, pp. 183-204, https://doi.org/10.1386/crre_00049_1

Hébert, C. (2015), 'Knowing and/or experiencing: A critical examination of the reflective models of John Dewey and Donald Schön', Reflective Practice, 16: 3, pp. 361-371.

Ingold, T. (2009), 'The textility of making', Cambridge Journal of Economics, 34: 1, pp. 91102.

Ingold, T. (2013), Making: Anthropology, Archaeology, Art and Architecture, London: Routledge.

Jakobson, B. and Wickman, P.-O. (2008), 'Art in science class vs science in art class: a study in elementary school', Éducation \& Didactique, 2: 3, pp. 141-157.

Kokko, S., Almevik, G., Høgseth, H. and Seitamaa-Hakkarainen, P. (2020), 'Mapping the methodologies of the Craft Sciences in Finland, Sweden and Norway', Craft Research, 11: 2, pp. 177-209.

Kouhia, A. (2015), 'The making-of: An autoethnographic cinema on the meanings of contemporary craft practicing for a young hobbyist', Textile: Journal of Cloth and Culture, 13: 3, pp. 266-283.

(2016), Unraveling the Meanings of Textile Hobby Crafts, Home Economics and Craft Studies Research Reports 42, Helsinki: University of Helsinki.

Lehmann, U. (2012), 'Making as knowing: Epistemology and technique in craft', The Journal of Modern Craft, 5: 2, pp. 149-164.

Mäkelä, M. (2007), 'Knowing through making: The role of the artefact in practice-led research', Knowledge, Technology \& Policy, 20: 3, pp. 157-163.

Mäkelä, M. and Nimkulrat, N. (2018), 'Documentation as a practice-led research tool for reflection on experiential knowledge', FORMakademisk, 11: 2, pp. 1-16.

Marchand, T. (2010), 'Making knowledge: explorations of the indissoluble relation between minds, bodies, and environment', Journal of the Royal Anthropological Institute, 16, pp. S1S21.

Nasseri, M. and Wilson, S. (2017), 'A reflection on learning crafts as a practice for selfdevelopment', Reflective Practice, 18: 2, pp. 194-205.

Niedderer, K. (2007), 'Mapping the meaning of knowledge in design research', Design Research Quarterly, 2: 2, 903922.

(2009), 'Relating the production of artefacts and the production of knowledge in research', in N. Nimkulrat and T. O'Riley (eds), Reflections and Connections: On the Relationship between Creative Production and Academic Research, Helsinki: University of Art and Design Helsinki, pp. 59-67.

(2013), 'Explorative materiality and knowledge: The role of creative exploration and artefacts in design research', FORMakademisk, 6: 2, pp. 13-33.

Niedderer, K. and Townsend, K. (2014), 'Designing craft research: Joining emotion and knowledge', The Design Journal, 17: 4, pp. 624-647. 
Lahti, Henna and Fernström, Päivi (2021), 'Crafticulation as a method of knowledge creation',

Craft Research, 12:2, pp. 183-204, https://doi.org/10.1386/crre_00049_1

Nimkulrat, N. (2010), 'Material inspiration: From practice-led research to craft art education', Craft Research, 1: 1, pp. 63-84.

(2012), 'Hands-on intellect: Integrating craft practice into design research', International Journal of Design, 6: 3, pp. 1-14.

Nonaka, I. and Takeuchi, H. (1995), The Knowledge-creating Company: How Japanese Companies Create the Dynamics of Innovation, New York: Oxford University Press.

Ojala, M., Karppinen, S. and Syrjäläinen, E. (2018), 'Towards making sense of self through emotional experiences in craft-art', Craft Research, 9: 2, pp. 201-27.

Pentassuglia, M. (2017), 'The Art(ist) is present: Arts-based research perspective in educational research', Cogent Education, 4: 1, 1301011.

Räisänen, R. (2014), 'How to visualize design? Pupils' experiences of designing in a textile craft project', Craft Research, 5: 2, pp. 199-219.

Sennett, R. (2008), The craftsman, New Haven: Yale University Press.

Skains, R. L. (2018), 'Creative practice as research: Discourse on methodology', Media Practice and Education, 19: 1, pp. 82-97.

Smith, H., and Dean, R. T. (2009), 'Introduction: practice-led research, research-led practice towards the iterative cyclic web', in H. Smith and R. T. Dean (eds), Practice-led Research, Research-led Practice in the Creative Arts, Edinburgh: Edinburgh University Press, pp. 1-38.

Thornquist, C. (2015), 'Material evidence: Definition by a series of artefacts in arts research', Journal of Visual Art Practice, 14: 2, pp. 110-119.

Throp, M. (2016), 'Correlating theory and practice in fine art research: Understanding practice as research; seminars for first year PhD students', Journal of Visual Art Practice, 15: 1, pp. 4-9.

Valentine, L. (2011), 'Craft as a form of mindful inquiry', The Design Journal, 14: 3, pp. 283-306.

Zmyślony, I. (2010), 'Various ideas of tacit knowledge-Is there a basic one?', in T. Margitay (ed.), Knowing and Being: Perspectives on the Philosophy of Michael Polanyi, Newcastle upon Tyne: Cambridge Scholars Publishing, pp. 30-49.

\section{Contributor details}

Henna Lahti (Ph.D., Docent of Craft Science) works as a university lecturer in the Department of Education, Faculty of Educational Sciences, at the University of Helsinki, Finland. She has been teaching sewing technology, clothing construction, pattern making and research methods since 2001. She has experience in supervising theses at the undergraduate, masters, and $\mathrm{PhD}$ levels. Her main research interest is in developing collaborative designing and crafting in various learning environments. She has published articles on collaborative design methods, virtual design studios, design thinking including material and embodied practices, and pedagogical aspects of collaborative designing. 
Lahti, Henna and Fernström, Päivi (2021), 'Crafticulation as a method of knowledge creation',

Craft Research, 12:2, pp. 183-204, https://doi.org/10.1386/crre_00049_1

Contact: Faculty of Educational Sciences, University of Helsinki, PO Box 8 (Siltavuorenpenger 10), FI-00014 Helsinki, Finland.

E-mail: henna.lahti@helsinki.fi

https://orcid.org/0000-0002-9242-3339

Päivi Fernström (Ph.D.) works as a university lecturer in the Department of Education, Faculty of Educational Sciences, at the University of Helsinki, Finland. She also has a position as Docent of Textile design at the University of Lapland in Finland. At the University of Helsinki, she has been teaching design teaching, exploratory and experiential weaving and embroidery, and research methods since 2002. She has experience in supervising theses at the undergraduate, masters and $\mathrm{PhD}$ levels. Her research areas are in textile and design history in dialogue with the present, design pedagogy, futures research, and artefact research.

Contact: Faculty of Educational Sciences, University of Helsinki, PO Box 8 (Siltavuorenpenger 10), FI-00014 Helsinki, Finland.

E-mail: paivi.fernstrom@helsinki.fi

https://orcid.org/0000-0002-0659-794X 